\title{
Innovated Malay Traditional Food Products: Do Consumers Accept the Authentic Quality?
}

Khairunnisa Mohamad Abdullah, Nor Rabiatul Adawiyah Nor Azam

To Link this Article: http://dx.doi.org/10.6007/IJARBSS/v11-i16/11228

DOI:10.6007/IJARBSS/v11-i16/11228

Received: 08 July 2021, Revised: 10 August 2021, Accepted: 27 August 2021

Published Online: 23 September 2021

In-Text Citation: (Abdullah \& Azam, 2021)

To Cite this Article: Abdullah, K. M., \& Azam, N. R. A. N. (2021). Innovated Malay Traditional Food Products: Do Consumers Accept the Authentic Quality? International Journal of Academic Research in Business and Social Sciences, 11(16), 199-208.

Copyright: (C) 2021 The Author(s)

Published by Human Resource Management Academic Research Society (www.hrmars.com)

This article is published under the Creative Commons Attribution (CC BY 4.0) license. Anyone may reproduce, distribute, translate and create derivative works of this article (for both commercial and non-commercial purposes), subject to full attribution to the original publication and authors. The full terms of this license may be seen

at: http://creativecommons.org/licences/by/4.0/legalcode

Special Issue Title: Contemporary Issues in Tourism and Hospitality industry, 2021, Pg. 199 - 208

Full Terms \& Conditions of access and use can be found at http://hrmars.com/index.php/pages/detail/publication-ethics 


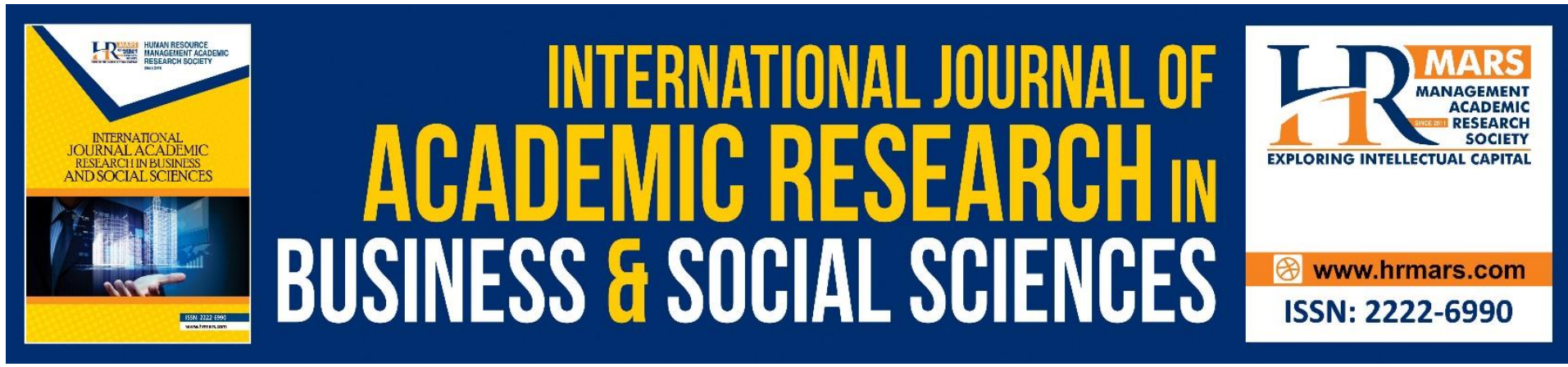

\title{
Innovated Malay Traditional Food Products: Do Consumers Accept the Authentic Quality?
}

\author{
Khairunnisa Mohamad Abdullah¹, Nor Rabiatul Adawiyah Nor \\ Azam² \\ ${ }^{1}$ Faculty of Hotel and Tourism Management, Universiti Teknologi Mara, Puncak Alam \\ Campus, Selangor, Malaysia, ${ }^{2}$ School of Tourism, Hospitality and Event Management, \\ Universiti Utara Malaysia, Malaysia \\ Email: khairunnisa1864@uitm.edu.my
}

\begin{abstract}
Innovation in Malay traditional food is somehow inevitable for the society in this modern era with their hectic lifestyle and limited time to prepare food from scratch. However, the implementation of innovation in traditional food is highly challenging as traditional and innovation are two elements that are considered contradict as the innovation may possibly ruin the authenticity and traditional characteristics of the foods. Therefore, this study investigated the perceived authenticity quality of innovated traditional Malay food products among Malaysian consumers will lead to better understanding. This study employed quantitative research design. The information needed for this study was obtained through self-administered questionnaire with 215 Malaysian consumers who have consume innovated Malaysian traditional food products with the age range from 18 till 60 years old. This study confirmed that majority of the consumers were positive towards innovations in traditional Malay food products particularly pertaining to sensory quality properties and ingredients content and revealed that perceived authenticity quality had a relatively strong influence on consumer acceptance. Therefore, it is crucial for the food manufacturer to not only strategically develop their innovation plan of action to better organize the scope of innovation categorization, but also be able to understand the importance of preserving the authenticity of the traditional foods character simultaneously.
\end{abstract}

Keywords: Food Innovation, Malay Traditional Foods, Consumer Acceptance, Food Authenticity

\section{Introduction}

Malaysian traditional foods have been formed and created through varying evolution and have faced no exception from innovation and modern technology advancement to cope with the latest society. The distinctive food cultures and cooking practices are deep-rooted in the acculturation of tradition, heritage and cooking practices of Malays, Chinese and Indians as the three major ethnic groups in Malaysia. Despite the assortment of traditional dishes available, innovation in Malay traditional food is somehow inevitable for the society in this modern era with their hectic lifestyle and limited time to prepare food from scratch. Conventionally, 
preparing traditional Malay foods from scratch commonly requires a lot of time, work and typically relatively high cost due to the variety of ingredients, which people nowadays try to avoid. Innovation is closely woven into the fabric of tradition and sooner or later, if not all, most of the Malay traditional foods will go through the stage of innovation.

Within the Malaysian food industry, there is an abundance of high-quality Malaysian food products produced by Malaysian food producers, especially traditional Malay foods, that can meet the international quality and packaging standards. These include instant paste and premix, canned products such as chicken rendang, curry, asam pedas, frozen products such as lemang, roti canai, otak-otak, variety of kuih, ready-to-eat food such as sambal, nasi lemak, ready to cook foods such as nasi impit, ketupat palas and many more. However, it is believed that many food entrepreneurs are too focused in the areas of production and very obsessive about producing food products with their own brand. Eventually, there are too many products that are very similar to each other even though the market is small, which will contribute to oversupply and lead to product failure and company bankruptcy. The government is also too focused on aiding entrepreneurs who have the capacity to produce their own products without looking at its market prospects. Innovation in the food industry confronts greater challenges compared to some other sectors and requires a high level of risk. Colurcio and Russo-Spena (2013) mentioned that within less than a year, nearly $40 \%$ to $50 \%$ of innovative food product introductions fail and lots of new product launches are out of the market's shelves (Henard \& Dacin, 2010). Gellynck and Molnár (2009); Jordana (2000) stated that the implementation of innovation in traditional food is highly challenging as traditional and innovation are two elements that are considered rivalry. Ludmila et al (2014) said that even if the consumer accepts the products, innovation may possibly ruin the authenticity and traditional characteristics of the foods. Therefore, the level of acceptance of traditional food products relies on the product itself and the innovation category that has been implemented.

Many studies have been performed to examine the underlying dimensions on the concept of food innovations, especially associated with innovation in technology-based in various fields pertaining to consumer acceptance, with results have shown that some consumers simply accept and reject the latest technology-based innovation (Lubberts, 2018; Dahan et al., 2015). In the case of the Malaysian context, no comprehensive studies have concentrated directly on consumer acceptance on the innovation of Malay traditional food products. Basically, many previous studies related to innovation highlighted more on the manufacturing sector, information and communications technology (ICT) and food products in general. As a result, no definite description is currently available on how consumers would accept innovated traditional Malay foods from the perspective of perceived authenticity quality. To lessen the gap of available literature, further study on the perceived authenticity quality of innovated traditional Malay food products among Malaysian consumers will lead to a better understanding. Therefore, investigating acceptance among consumers to accept or reject innovated traditional Malaysian food products would become strategic to safeguard the Malay traditional food and the Malaysian food sector simultaneously.

\section{Literature Review \\ Innovation in Traditional Food}

Innovation in traditional food is the assimilation of new concept on traditional food products by enhancing the product's perceptual characteristic including the improving of 
traditional quality, cutting up the content of fat, distinct packaging, withdrawing the unnecessary flavour, upgrading the product presentation to be more authentic and selling the product through vending machines to create a new facet of traditional food product (Stanton, 2016; Winger \& Gavin, 2006). Youn and Kim (2017) added some of the possible reasons for innovation in traditional foods: the requirement and demand for safety and preservation, improvement in keeping quality, practical and convenient packaging, and the production processes of industrialization. Amilien and Hegnes (2013) mentioned that the preservation, processing, and improvement of food safety and hygiene had facilitated the traditional techniques through the implementation of advanced technologies. The study by Sharif et al. (2017) also revealed that consumer decisions to purchase food products are constructed through varying trait measures that could be categorized into intrinsic attributes such as taste, appearance, odour, colour, and extrinsic characteristic including product's image, brand, origin, and labeling of food product. In order to retain market acceptance, the essential rule for innovative traditional food product is the authentic characteristic of the food, especially the ingredients and sensory attributes that are not altered without attentive deliberation (Almli et al., 2011).

\section{Perceived Authenticity of Innovated Traditional Food Products}

Food authenticity is described as the genuine and originality of food in several aspects (Borghini, 2013; Özdemir \& Seyitoğlu, 2017). It is also a significant component in representing a community's culture, family identity, and tradition (Hamzah et al., 2013). Guiné et al. (2016) added that additional core component of food authenticity exists within the individual. These 'personal' features encompass the cultural knowledge and awareness of the consumers on what is considered as food authenticity. Even though many efforts are taken to maintain the authenticity of traditional foods, consumers' demands become the challenge and force the industry to merge the traditional foods with a more advanced and modern touch. Still, they try to sustain the traditional character of the foods despite the shifting of the food consumption due to the revolution and modernization so that the food just tastes 'right'. In relation to traditional food segment, Kallas et al (2018) stated that the best accepted innovation in traditional food is the one that provided benefits, but neither affected the traditional image nor the characteristic sensory properties of the product. Multiple studies have recognised the foods' sensory qualities as the utmost important aspect in food choice (Cayot, 2007; Ludmila et al., 2014). As cited by Wong and Said (2017), consumer evaluation of food products is mostly influenced by sensory characteristics. The physicochemical components are made of taste, texture, colour, formulation alteration, and freshness. Consumers have the capacity to choose whether they like or reject the food products once they have consumed and experienced their sensory features. This is supported by Maina (2018) in which the sensory properties of food, such as taste, scent, texture, and appearance, have strong consequences on consumers' preference. This is further reinforced by Sharif et al (2017); Konuk (2019) in which the food sensory properties, including taste, aroma, texture and appearance, are vital before, during and after the consumption. These components draw consumers towards the food origin, preferences, choices, and satisfaction with the food they eat. In addition, Almli et al (2011) explained that to retain market acceptance, the essential rule for an innovative traditional food product is the authentic characteristic of the food, which is that the sensory attributes are not altered without attentive deliberation. 
Furthermore, authentic ingredients also impact the expectations of authenticity of most individuals on the different characteristics that distinguish conventional or ethnic cuisine (Amilien \& Hegnes, 2013; Asshidin et al., 2016). In specific, food ingredients that are unique or locally sourced are crucial to traditional food authenticity (Ismah et al., 2014; Latif, 2018). Fajans (2006) also mentioned that food ingredients contribute significantly to traditional food as it encompasses nutritive value that is essential in consumers' day-to-day food intake. He also said that the usage of such ingredients that are common to locals will substantially affect the evaluation of food authenticity by consumers. It is constant with the belief that these distinctive and/or familiar characters foster authenticity impressions and raise preferences for authentic food experiences. Hamzah et al. (2013) specified that only consumers who are familiar and accustomed with the food and culture of the ethnic origin are able to assess its authenticity and tend to reject unfamiliar food products.

\section{Consumer Acceptance of Innovated Traditional Food}

From consumers' viewpoint, perceived quality is considered intricate in food products perspective and is frequently influenced by various aspects of constructs in which evaluation requires the construction of adequately appropriate evaluation (Asshidin et al., 2016; Khan, 2019; Zhang et al., 2019). Therefore, it is important to adapt the evaluation according to individual product attributes as the effect of the differentiation will vary from expectation. The acceptance level is highly determined by the type of innovation applied to traditional food products from food innovation perspectives. Traditional food firms should be more alert particularly to the sensory modification of traditional food products, as any changes of sensory properties despite their potential benefits may reduce the value and acceptance of innovated traditional food (Kallas et al., 2018). Barrena et al. (2015) studied the consumers' decision structures of different ages pertinent to innovative traditional food products to identify potential dissimilarity, which proves that young consumers have high acceptance and consumption on innovative traditional food consistent with many previous results. Furthermore, Baregheh et al. (2014) postulated that young consumers tend to perceive more value from attributes of innovated food and the features are believed to provide greater influence on their personality. Vanhonacker et al. (2010) tested the innovation of traditional food character among consumers. This study, in general, proved that most of them were positive towards innovation in traditional food products. However, the acceptance depended on the innovation type connected to strengthening the traditional features; for example, the label that guarantees the ingredient source or gains advantage that either compensates the significant traditional features or reduces undesirable characteristics related to the traditional characters like fat content reduction. Yet, the study also revealed that most consumers were more skeptical about technologies relating to new distribution channels to sell traditional food products such as the use of vending machine.

\section{Methodology}

This study employed quantitative research design. The information needed for this study was obtained through a self-administered questionnaire from Malaysian consumers aged 18 to 60 years old who have consumed innovated Malaysian traditional food products to provide relevant information on the particular subject. Majority of the items were adjusted from the past studies on parallel topic to accomplish the study's goal (Almli et al., 2011; Barcellos et al., 2009; Guerrero et al., 2008). The initial section dealt with the demographic information of the samples, including age, gender, education, and marital status. Section B was formed to test 
five items' perceived authentic quality (taste, smell, texture, appearance, ingredients). Finally, the five items in section $C$ assessed the consumers acceptance. The five-point Likert scale was used with 1 denoting "strongly disagree," and 5 signifying "strongly agree" to gather the response from the respondents. Entire information collected was entered into Statistical Package for Social Science (SPSS) version 23 to decipher the information. During the process of information screening, only 215 were useful responses. In this manner, descriptive statistical examination was applied to figure out the frequencies, rate, mean score, and standard deviation to report the variables' data. The standard multiple regression was utilized in deciding how the impact of nutritive value attributes described much variance in food preparation and consumption among chefs. A pilot survey with 32 respondents was performed to assess the reliability and the final items were slightly modified based on their input

\section{Result and Analysis}

This section of analysis looked into the Perceived Authentic Quality of Innovated Traditional Malay Foods. The mean score is depicted in Table 4.1 below.

Table 1: Perceived Authentic Quality of Innovated Traditional Malay Foods Perceived Authenticity Mean N Deviation

1. The taste and flavor of $3.8 \quad .43 \quad 215$ innovated traditional Malay food products is similar to the authentic traditional Malay foods

2. The appearance and shape of $4.4 \quad .54 \quad 215$ innovative traditional Malay foods are similar to the authentic traditional Malay foods

3. The texture of the products is $3.5 \quad .45 \quad 215$ similar to authentic traditional Malay foods.

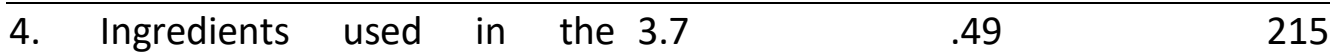
products are authentic and similar to the Traditional Malay foods

5. When I eat food products, it 3.15 .41 215 reminds me of the nostalgic feelings with my family.

Results in Table 1 show that majority of the consumers slightly agreed that the taste and flavour ( $M=3.8)$, appearance $(M=4.4)$ and texture $(M=3.5)$ of innovated traditional Malay food products were similar to the authentic traditional Malay foods. They also somewhat agreed that the ingredients used in the products were authentic and similar to the traditional Malay foods ( $M=3.7)$. In addition, when they ate the food products, it somehow reminded them the nostalgic feelings with their family (3.15). 


\section{Consumer Acceptance on Innovated Traditional Malay Foods}

This section discusses the general consumer acceptance of innovated traditional Malay foods. The respondents were required to answer each item relating to their overall acceptance of innovated traditional Malay foods products using a five-point Likert scale. The mean score and standard deviation were tabulated in the table below.

Table 2: Mean Score of the Consumer Acceptance on Innovated Traditional Malay Foods Perceived Authenticity Mean Standard $\mathbf{N}$

\begin{tabular}{llccc}
\hline 1. I like and enjoy the taste and & 3.45 & .43 & 215 \\
texture of the products & & .55 & 215 \\
\hline $\begin{array}{l}\text { The appearance of the } \\
\text { innovative traditional food } \\
\text { products looks appetizing }\end{array}$ & 4.62 & .52 & 215 \\
\hline $\begin{array}{l}\text { I will purchase the product } \\
\text { again in the future }\end{array}$ & 4.10 & .47 & 215 \\
\hline 4.. I will recommend the & 3.30 & .56 & 215 \\
\hline products to others & $\begin{array}{l}\text { I am satisfied with the overall } \\
\text { quality of the product }\end{array}$ & 4.05 & &
\end{tabular}

Table 2 shows that majority of the respondents slightly liked and enjoyed the taste and texture of the products (Mean =3.45). But they strongly agreed that the appearance of the innovated traditional food products looked appetizing (Mean $=4.62)$. The mean score of $(M=$ 4.1) showed that the respondents would purchase the product again in the future and possibly will recommend the products to others $(M=3.3)$. Overall, they were satisfied with the quality of the products $(\mathrm{M}=4.05)$.

\section{Relationship between Perceived quality and Consumer Acceptance on Innovated Traditional Malay Foods}

Standard multiple regression further analysed the relationship between perceived authentic quality and consumer acceptance on innovated traditional Malay foods. The beta value under standardized coefficient was assessed by linking the contribution of the independent variables to the dependent variable. The result signified that Perceived Authentic quality was able to clarify 72 percent $(p<.001)$ of the variance in consumer acceptance of innovated traditional Malay foods. By looking at the beta value, perceived authentic quality $(\beta=76, p=0.00)$ had a relatively strong influence on consumer acceptance of innovated traditional Malay foods. 
Table 3: Multiple Regression Result

\begin{tabular}{|l|l|}
\hline $\begin{array}{l}\text { Multiple Regression result on Dependent Variable (DV) } \\
\text { Consumer Acceptance on Innovated Traditional Malay Foods }\end{array}$ \\
\hline \multicolumn{1}{|l|}{ Independent variable } & Beta Coefficients and Significance Levels \\
\hline Step 1: Model variable & \\
Perceived Authenticity quality & $.76^{* * *}$ \\
R2 & .715 \\
Adj.R2 & .713 \\
R2 change & .105 \\
F-change & 141.81 \\
\hline
\end{tabular}

\section{Conclusion}

As revealed in the above sections, the result showed to what extent perceived authentic quality impacted innovation acceptance (or rejection) of traditional Malay foods. Overall, this study confirmed that the majority of the consumers were positive towards innovations in traditional Malay food products, particularly sensory quality properties and ingredients content. Results also showed that perceived authentic quality had a relatively strong influence on consumer acceptance of innovated traditional Malay foods. Relying on the quality characteristics of the innovation, it is important to improve and retain the traditional character of authentic Malay foods as much as possible in the innovation in terms of sensory properties of the products specifically the taste, flavor and texture. On food manufacturers standpoint, they must maximize the sensory qualities of their products as perceived by their customers. This significantly enhances the perceived value of the product across distinct consumers. Besides that, consumers' acceptance is critical for food producer and marketer as they have spent substantial budgets on research and development of new food products development and marketing. It is also crucial for the food manufacturer to strategically develop their innovation plan of action to organize the scope of innovation categorization better and understand the importance of preserving the authenticity of the character of the traditional food simultaneously.

\section{Corresponding Author}

Khairunnisa Mohamad Abdullah

Faculty of Hotel and Tourism Management, Universiti Teknologi Mara, Puncak Alam

Campus, Selangor, Malaysia

Email: khairunnisa1864@uitm.edu.my

\section{References}

Almli, V., Verbeke, W., Vanhonacker, F., Næs, T., \& Hersleth, M. (2011). General image and attribute perceptions of traditional food in six European countries. Food Quality and Preference, 129-138. doi:10.1016/j.foodqual.2010.08.008

Amilien, V., \& Hegnes, A. (2013). The dimensions of 'traditional food' in reflexive modernity: Norway as a case study. Journal of the Science of Food and Agriculture, 93. doi:10.1002/jsfa.6318

Asshidin, N. H., Abidin, N., \& Borhan, H. (2016). Perceived Quality and Emotional Value that Influence Consumer's Purchase Intention towards American and Local Products. Procedia Economics and Finance, 35, 639-643. doi:10.1016/S2212-5671(16)00078-2 
Barcellos, M. D. D., Aguiar, L. K., Ferreira, G. C., \& Vieira, L. M. (2009). Willingness to try innovative food products: a comparison between British and Brazilian consumers. BAR - Brazilian Administration Review, 6, 50-61. Retrieved from http://www.scielo.br/scielo.php?script=sci_arttext\&pid=S180776922009000100005\&nrm=iso

Baregheh, A., Hemsworth, D., \& Rowley, J. (2014). Towards an Integrative View of Innovation in Food Sector SMEs. The International Journal of Entrepreneurship and Innovation, 15. doi:10.5367/ijei.2014.0152

Barrena, R., García, T., \& Camarena, D. (2015). An Analysis of the Decision Structure for Food Innovation on the Basis of Consumer Age. International Food and Agribusiness Management Review, 18, 149-170.

Borghini, A. (2013). Authenticity in Food. In P. B. Thompson \& D. M. Kaplan (Eds.), Encyclopedia of Food and Agricultural Ethics (pp. 1-6). Dordrecht: Springer Netherlands.

Cayot, N. (2007). Sensory quality of traditional foods. Food Chemistry, 101, 445-453. doi:10.1016/j.foodchem.2006.10.016

Colurcio, M., \& Russo-Spena, T. (2013). Collaborative Innovation A Focus on Food SMES.

Fajans, J. (2006). Regional food and the tourist imagination in Brazil. Appetite, 47, 389-389. doi:10.1016/j.appet.2006.08.020

Gellynck, X., \& Molnár, A. (2009). Chain governance structures: The European traditional food sector. British Food Journal, 111, 762-775. doi:10.1108/00070700910980900

Guerrero, L., Guàrdia, M. D., Xicola, J., Verbeke, W., Vanhonacker, F., Zakowska-Biemans, S., ... Hersleth, M. (2008). Consumer-driven definition of traditional food products and innovation in traditional foods. A qualitative cross-cultural study. Appetite, 52, 345354. doi:10.1016/j.appet.2008.11.008

Guiné, R., Ramalhosa, E., \& Cruz-Lopes, L. (2016). New foods, new consumers: Innovation in food product development Running title: Innovation in Food Development. Current Nutrition \& Food Science, 12, 175-189. doi:10.2174/1573401312666160608120727

Hamzah, H., Ab Karim, M., Othman, M., \& Hamzah, A. (2013). Dimensions of Authenticity in Malay Cuisine from Experts' Perspectives. Academic Journal of Interdisciplinary Studies. doi:10.5901/ajis.2013.v2n3p369

Henard, D., \& Dacin, P. (2010). Reputation for Product Innovation: Its Impact on Consumers*. Journal of Product Innovation Management, 27, 321-335. doi:10.1111/j.15405885.2010.00719.x

Ismah, O., Osman, S., Mokhtar, I., Setapa, F., Shukor, S., \& Temyati, Z. (2014). Family Food Consumption: Desire towards Convenient Food Products. Procedia - Social and Behavioral Sciences, 121, 223-231. doi:10.1016/j.sbspro.2014.01.1123

Jordana, J. (2000). Traditional foods: challenges facing the European food industry. Food research international (Ottawa, Ont.), 33(3/4), 147-152. doi:10.1016/s09639969(00)00028-4

Kallas, Z., Vitale, M., Candek-Potokar, M., Lebret, B., Pugliese, C., Cerjak, M., . . Gil, J. M. (2018, July 28-August 2, 2018,). Are Food Neophobic Consumers Reluctant to Innovative Traditional Pork Products? An Analysis in Six European countries using A Non-Hypothetical Choice Experiment. Paper presented at the International Association of Agricultural Economists (IAAE) > 2018 Conference Vancouver, British Columbia. 
Khan, T. (2019). The impact of perceived quality on consumer attitude in food industry of Pakistan. Turkish Journal of Marketing, 3, 181-198. doi:10.30685/tujom.v3i3.57

Konuk, F. A. (2019). The influence of perceived food quality, price fairness, perceived value and satisfaction on customers' revisit and word-of-mouth intentions towards organic food restaurants. Journal of Retailing and Consumer Services, 50, 103-110. doi:https://doi.org/10.1016/j.jretconser.2019.05.005

Latif, Z. A. (2018). The effect of perceived authenticity of food towards experience and place attachment at the State Fair (Doctoral dissertation, lowa State University).

Lubberts, T. (2018). The Impact of Product Cue Manipulation and Consumer Product Involvement on Product Authenticity Evaluations. (MSc Thesis Marketing and Consumer Behavior). Wageningen University.

Ludmila, I., Trifonova, J., \& Terziyska, I. (2014). Characteristics of traditional food - the viewpoint of the tourism business. Service Management, 14, 123-130.

Maina, J. (2018). Analysis of the factors that determine food acceptability.

Mat Dahan, S., Noor Kamar, A. N., Syuhada, H., Zainudin, M. N., \& Ismail, F. (2015). The Determinants of Innovation in Malaysian Food Processing Small and Medium Enterprises (SMEs).

Özdemir, B., \& Seyitoğlu, F. (2017). A conceptual study of gastronomical quests of tourists: Authenticity or safety and comfort? Tourism Management Perspectives, 23, 1-7. doi:https://doi.org/10.1016/j.tmp.2017.03.010

Sharif, M., Butt, M., Sharif, H., \& Nasir, M. (2017). Sensory Evaluation and Consumer Acceptability. In (pp. 362-386).

Stanton, J. L. (2016). Food Innovation: The Good, the Bad and the Ugly. Management, 11(3), 193-202. Retrieved from https://EconPapers.repec.org/RePEc:mgt:youmng:v:11:y:2016:i:3:p:193-202

Vanhonacker, F., Almli, V., Hersleth, M., \& Verbeke, W. (2010). Profiling European traditional food consumers. British Food Journal, 112, 871-886. doi:10.1108/00070701011067479

Winger, R., \& Gavin, W. (2006). Food product innovation. Rome.

Wong, S. S., \& Said, M. A. (2017). Factors influencing purchase intention of organic meat among consumers in Klang Valley, Malaysia. International Food Research Journal, 24, 767-778.

Youn, H., \& Kim, J.-H. (2017). Effects of ingredients, names and stories about food origins on perceived authenticity and purchase intentions. International Journal of Hospitality Management, 63, 11-21. doi:10.1016/j.ijhm.2017.01.002

Zhang, T., Chen, J., \& Hu, B. (2019). Authenticity, Quality, and Loyalty: Local Food and Sustainable Tourism Experience. Sustainability, 11, 3437. doi:10.3390/su11123437 